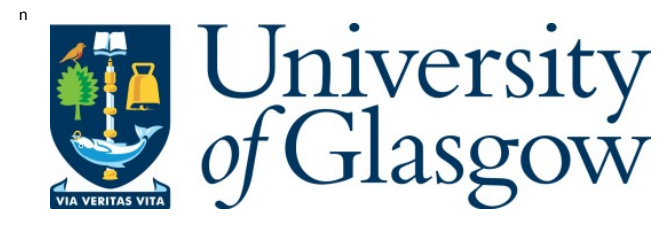

Solomon, T. (2014) The affective underpinnings of soft power. European J ournal of International Relations, 20 (3). pp. 720-741. ISSN 1354-0661

Copyright (c) 2014 Sage Publications

A copy can be downloaded for personal non-commercial research or study, without prior permission or charge

Content must not be changed in any way or reproduced in any format or medium without the formal permission of the copyright holder(s)

http://eprints.gla.ac.uk/86112/

Deposited on: 19 December 2014

Enlighten - Research publications by members of the University of Glasgow http://eprints.gla.ac.uk 


\section{The Affective Underpinnings of Soft Power}

The concept of soft power occupies a prominent place in IR, foreign policy, and security studies. Primarily developed by Joseph S. Nye, the concept is typically drawn upon to emphasize the more intangible dimensions of power in a field long dominated by overtly material (i.e. military) power. Recently some scholars have re-framed soft power - specifically the key notion of attraction - as a narrative and linguistic process. This literature, however, has downplayed some of the other deepseated underpinnings of soft power, which this article argues lie in the dynamics of affect. Building upon the IR affect and aesthetics literatures, this paper develops the concept of soft power as rooted in the political dynamics of emotion and introduces the concept of affective investment. The attraction of soft power stems not only from its cultural influence or narrative construction, but more fundamentally from audiences' affective investments in the images of identity that it produces. The empirical import of these ideas is offered in an analysis of the construction of American attraction in the war on terror.

In her confirmation hearings in January 2009 before the US Senate Foreign Relations

Committee, Secretary of State Hillary Clinton argued that to deal with a multiplicity of pressing global issues, the US “must use what has been called 'smart power': the full range of tools at our disposal -- diplomatic, economic, military, political, legal, and cultural -- picking the right tool, or combination of tools, for each situation (Clinton 2009). Clinton used the phrase four times in her remarks, each time emphasizing that not every foreign policy dilemma is a military nail in need of a hammer of material force. In one sense, this was likely a conscious move on the part of the new administration to distance itself from what it viewed as the excesses of the Bush administration. In another sense, "smart power" was a slight rhetorical shifting of the more well-known concept of soft power. The day following the confirmation hearing the New York Times (2009) website ran a feature entitled "How 'Soft Power' Got 'Smart'." The Times noted that while some in the hearing seemed to grow tired of Clinton's repetition of the phrase, ${ }^{1}$ the term's better-known incarnation is the product of Joseph S. Nye's longtime writings advocating its use in foreign policy. Nye himself recently elaborated upon "smart power" as "the combination of the hard power of coercion and payment with the soft power of persuasion and attraction" (Nye 2011: xiii). 
Additionally, soft power has long been a staple within academic International Relations (IR). Not only have many of Nye's own seminal works centered on the concept $(1990 ; 1991$; $2002 ; 2004 ; 2011)$, but many other scholars have astutely explored the ability of various states to deploy it, its conceptual ambiguities, and the mechanisms through which it often works (Bohas 2006; Hayden 2012; Hocking 2005; Kroenig, McAdam, and Weber 2010; Parmar and Cox 2010; Sun 2012; Wang and Lu 2008). While much of this insightful literature has been useful in elaborating soft power's advantages and limits, most work on the concept has - somewhat curiously - neglected the potential affective and emotional roots of soft power. This paper argues that much of the deep-seated conceptual and political underpinnings of soft power lie in the dynamics of affect. Insofar as the main appeal and social mechanism of soft power "comes from attraction" (Nye 2004: 6), such a lure is often bound up with the politics of affect and emotion. Building upon the growing literatures on affect and aesthetics in IR, and drawing upon the political theory of Ernesto Laclau, this paper probes some of these key - yet hitherto underanalyzed - social underpinnings of soft power. It argues that closely related to Nye's contention that soft power stems from "culture, political values, and foreign policies" (2004: 11), much of the appeal of soft power derives from the affective and aesthetic dynamics in the social construction of identity - and the investments audiences make in such identities. As argued below, the notion of affective investment provides a conceptual anchor to more fully grasp the efficacy of soft power, and that the emotional pull of attraction offers a more comprehensive understanding of the social dynamics at stake in soft power practices. Put differently, the power of soft power may be more fruitfully unpacked by interrogating some of the very "intangibles" of social and political life that first prompted Nye's important statements on the concept. Consequently, this paper aims at cultivating and enhancing our understanding of the theoretical bases of soft power, and thus 
largely leaves for future work the task of detailing more specific methodologies for the study of affect and soft power.

More broadly, an investigation into the role of affect and aesthetics in the working of soft power offers implications for the literature on power in general. While long a core disciplinary concept, recent work has delved into the social aspects of power, a development which is notable for a field long concerned with material (e.g., military) power. In concluding their essay on conceptual typologies of power, Barnett and Duvall (2005: 67) "urge scholars to see how the multiple concepts [of power] capture the different and interrelated ways in which actors are enabled and constrained in determining their circumstances." This call for engagement between different approaches to power has been shared by others in recent years (see Berenskoetter and Williams 2007) including Nye himself (2007). Put into Barnett and Duvall's (2005: 42, emphases added) terms, bringing affect into the debates on power (here, by way of soft power) helps to more fully draw out one of the key axes around which the concept coheres, that power is "either an attribute of particular actors and their interactions or a social process of constituting what actors are as social beings, that is, their social identities and capacities." A focus on affect speaks directly to both of these dimensions, as affect plays a role in both the interactions between actors in particular contexts (see Fatah and Fierke 2009; Sasley 2010), and is involved in the social construction of subjects themselves (see Solomon 2012). In more explicitly theorizing these affective dynamics of attraction and power, this study concurs with Watanabe and McConnell's (2008: xxiv) analytical concern with "the ways in which 'attraction' is codetermined" between agent and target. More broadly, the article follows Lukes's (2005: 492) suggestion that power analyses ask "how do agents succeed in winning the hearts and minds of those subject to their influence?" In integrating affective dynamics into the workings of soft power, this article 
introduces the - often-implied but rarely analytically unfolded - concept of affect to the study of power in IR more broadly.

The article proceeds as follows. First, I review Nye's development of the concept, focusing on his definition of and his arguments about the roots of soft power. Second, I examine relevant works that probe some of the conceptual foundations of soft power. While much research relates to soft power's policy implications (see Melissen 2005), and many lament what they see as its conceptual fuzziness, there is still significant work to be done in sustained theoretical development of the concept. While Nye (2004: 5) is explicit in arguing that much of the appeal of soft power lies in "attraction," he and others neglect to develop an adequate theorization of this key factor. An exception is the recent trend toward analyzing soft power and attraction as narrative-based phenomena, particularly the work of Hayden (2012) and Bially Mattern (2005). Third, following a critique of Hayden, Bially Mattern, and the IR discourse and identity literature more broadly, I conceptually develop some of the hitherto neglected affective and aesthetic aspects of soft power, drawing upon Laclau's notion of affective investment. In analyzing the politics of discourse, Laclau draws a key distinction between "form" and "force." That is, most contemporary approaches to discourse analyze the linguistic "forms" which structure identities at the expense of conceptualizing the affective and emotional "force" that are often bound up with such structures and gives them their appeal. This distinction is crucial to understanding the relationship between discourse and affect, a relationship which is crucial to more fully understanding how soft power practices of attraction emotionally resonate with audiences. Next, the paper offers an empirical illustration of these conceptualizations through analyzing US efforts to construct itself as "attractive" in the post-9/11 war on terror. Finally, the conclusion reiterates the paper's main arguments, and suggests potential routes for future research.

\section{Soft Power in IR Theory}


Nye originally introduced the concept of soft power in the early 1990s in part to contend with what he saw as the changing nature of the international system. He originally defined soft power as what happens "when one country gets other countries to want what it wants ... in contrast with the hard or command power of ordering others to do what it wants" (Nye 1990: 166, emphasis in original). Indeed, while policymakers and scholars had been focused throughout the Cold War on the hard power of military capabilities, Nye saw the 1990s usher in an era where this hard power focus would prove increasingly less important. "The factors of technology, education, and economic growth are becoming more significant in international power, while geography, population, and raw materials are becoming somewhat less important," Nye (1990: 154) contended. Thus, in a world where hard power would prove less effective, "it is just as important to set the agenda and structure the situations in world politics as to get others to change in particular cases" (Nye 1990: 166). Consequently, Nye advocated that the US should focus much more on cultivating its soft power capabilities in the post-Cold War environment. As he (1990: 167) contends, if "a state can make its power seem legitimate in the eyes of others, it will encounter less resistance to its wishes." According to Nye, this capacity stems from "three resources: its culture (in places where it is attractive to others), its political values (when it lives up to them at home and abroad), and its foreign policies (when they are seen as legitimate and having moral authority)" (2004: 11). Yet such resources do not automatically influence others to "want what you want," but must be realized through actions aimed at achieving particular influence. For Nye (2011: 16), soft power is the "ability to get preferred outcomes through co-optive means of agenda-setting, persuasion, and attraction." The setting of an agenda in such a way as to highlight some issues while keeping others out of sight and the mechanisms of persuasion both offer important alternatives to hard power. 
Although the political sources of soft power may lie in cultural influence, values, and morally legitimate foreign policies, for Nye the core factor lies in what he calls "attraction.", Indeed, as Hayden (2012: 29) finds, "attraction is clearly the archetypical soft power behavior." For example, Nye (2004: 6) notes "political leaders have long understood the power that comes from attraction. If I can get you to want what I want, then I do not have to use carrots or sticks to make you do it." One may "appeal to my sense of attraction, love, or duty in our relationship" in order to achieve one's goals (Nye 2004: 7). Moreover, attraction rarely constitutes direct outcomes, but rather "has a diffuse effect, creating general influence rather than producing an easily observable specific action" (Nye 2004: 16). "At a personal level, we are all familiar with the power of attraction" (Nye 2004: 5). Yet, as Nye (2011: 91-2) acknowledges, attraction “is more complex than it first appears," since "it can refer to drawing attention - whether positive or negative - as well as creating alluring or positive magnetic effects." With state actors, "clusters of qualities" such as "benignity, competence, and beauty (charisma)" are often key in influencing others' in one's preferred direction (Nye 2011: 92). In this sense, Nye's (2011: 92) concern with the constituent qualities of attraction point toward the social aspects of soft power: "the production of soft power by attraction depends upon both the qualities of the agent and how they are perceived by the target."

Despite the centrality of attraction to soft power, Nye neglects to more fully theorize what mechanisms attraction actually entails. Indeed, downplaying the emotional and aesthetic dimensions of attraction is a curious omission for Nye and others who have elaborated upon soft power or lamented its conceptual fuzziness. In discussing attraction Nye mentions how in a relationship "power does not necessarily reside with the larger partner, but in the mysterious chemistry of attraction" (2004: 5), that the "ability to establish preferences tends to be associated with intangible assets such as an attractive personality, culture, political values and institutions, 
and policies that are seen as legitimate or having moral authority (2004: 6), and that "if my behavior is determined by an observable but intangible attraction . . . soft power is at work" (2004: 7). "Mysterious chemistry," "intangible assets," "intangible attraction" - in attempting to name the often ineffable qualities that constitute attraction, Nye rightly points to (albeit, without much theoretical interrogation) the very affective and aesthetic aspects which are likely a key factor in understanding the political efficacy of attractiveness.

This neglect is one of the main critiques leveled by some of Nye's recent critics, notably Hayden (2012) and Bially Mattern (2005). As Hayden (2012: 43) contends, the "idea of 'attraction' ... rests on some unelaborated assumptions about how agent characteristics can be translated into soft power outcomes." Additionally, Bially Mattern (2005: 584) asks "what exactly is it that makes an idea attractive or appealing in the first place? . . How, the question is, does attraction happen?" For our purposes, both of these authors are key because they engage the concept of attraction within a specific discussion of soft power. More importantly, these are the few studies in the soft power scholarship which conceptualize it as a narrative- and linguisticbased phenomena. As argued below, this is a key theoretical move in specifying the mechanisms by which soft power works, but it is nevertheless a move that has downplayed the emotional aspects of soft power. Furthermore, these gaps, it is argued, are symptomatic of larger shortcomings in how IR conceptualizes discourse and identity.

Hayden (2012: 43) argues that attraction "is probably better understood as a form of symbolic, influence-oriented communication that operates in both the passive and active sense of soft power." Attraction can be an active strategy of cultivating those qualities that are believed to be appealing, yet it can also encompass a more diffuse sense of allure that can influence without direct action. To understand soft power as relational between agents and targets is to "underscore the importance of how specific qualities of the agent are perceived by 'targeted' subjects (Hayden 
2012: 44). Indeed, Nye (2011: 92) contends that qualities such as competence can command "admiration, respect, and emulation," and that the perceived "beauty" and "charisma" of an agent tend to "produce inspiration and adherence" on the part of a target audience when effective. Attraction, in Hayden's (2012: 45, emphasis in original) reading, "is presented as a reaction to compelling attributes." Consequently, Hayden argues that attraction can be more fruitfully conceptualized through a framework of language and identity. As he (2012: 45) contends, the actions involved in attraction are better thought of "as those that cultivate 'identification' ... Attraction is not persuasion per se, but resultant from representation acts that symbolize shared worlds." While this involves variations in different contexts, reframing attraction around language and identity offers some helpful conceptual clarity regarding soft power. Nye's argument about attraction, in this sense, "is not a rigidly denotative category of power behavior, but rather a statement about how agents and subjects [targets] relate to each other in ways that are constitutive of their identity" (Hayden 2012: 46, emphasis in original). "Attraction is implicitly presented as a rhetorical tool" by Nye, as an intersubjective framework that can act as "an invitation to recognize a shared experience of being and perspective" (Hayden 2012: 46, 45).

Bially Mattern (2005) raises similar issues. She astutely points out that Nye "theorizes attraction as a natural objective experience when he describes the allegedly universally attractive values of cosmopolitanism, democracy, and peace. On the other hand, Nye implies that attraction is a social construct; he emphasizes the utility of public diplomacy for 'converting' foreigners so that they become attracted to one's own values" (Bially Mattern 2005: 591). Nye thus builds shaky foundations by mixing essentialist and constructivist ontological assumptions. Bially Mattern rejects Nye's assumption of the possibility of natural attraction, and instead argues that attraction is constructed through language. Bially Mattern contends that the primary dynamic of soft power based on how actors deploy their preferred representations of political "reality." How 
an actor deploys his/her rhetorical strategy is based not on pre-given interests, but are more deeply linked to their narratively-constructed Self. Since an actor's identity is a socio-linguistic construct (rather than being naturally-given), an actor's "interpretation[s] of a given thing in the world ... are not just disinterested observations, but precious traces of [his/her] own subjectivity" (Bially Mattern 2005: 600). Bially Mattern argues that actors will deploy those representations that threaten target audiences' sense of Self. This does not entail a physical threat, but instead strategically places the target audiences' sense of Self - the narrative constituting how an audience or group sees itself - in a vulnerable position with no choice but to accept the speaker's own particular representation of reality (Bially Mattern 2005: 602). Attraction, in this perspective, is not "soft" as Nye contends. Rather, attraction is a socio-linguistic construct which can be deployed to "threaten" the vulnerabilities in an audiences' sense of Self.

Taken together, then, both Hayden and Bially Mattern rightly point out Nye's conceptual ambiguity on attractiveness. And, both contend that the power of attractiveness largely rests upon the dynamics of language and identity. However, they downplay an important dynamic that would seem to surely be at work in an account of attractiveness in soft power - the role of affect/emotion. This gap arises in both authors' analyses. Hayden (2012: 47), for example, argues that when actors work to exert soft power capacities, "they may affirm or cultivate bonds of value identification across audiences and impact normative guidelines for international behavior ..." In other words, insofar as a target audiences' "values" are prized by them, some type of investment or attachment would seem to be the fortifying element at work that is the effective target of soft power efforts. In other words, it must ultimately be this investment in values themselves (an investment that elevates them as values in the first place) that must be fostered if a shared identification will be produced. Similarly, Bially Mattern's analysis touches upon but in effect overlooks the same issue. Since targets wish to protect their narratively-constructed Self, they 
may be coerced by strategic language such that they are forced to admit a speaker's representation of reality or else risk damage to their Self. For example, where US officials frequently deployed the forceful language of "you are either with us or against us" in the war on terror, Bially Mattern (2005: 606) argues that for "members in the audience whose subjectivities depended in important part on narrative 'realities' about being on the 'good' side of the good/evil divide, this creates a trap" of having to side with the US or deny the narrative that constructed their "goodness." While steering clear of Nye's essentialism, this conceptualization downplays the likely role of affect/emotion in the construction of attraction. In this account, if US constructions of its attractiveness were successful because audiences' subjectivities "depended" upon placing themselves within the "good" side of a good/evil binary, then there must have been some sort of investment in understanding themselves as such. Audiences' subjectivities presumably did indeed "depend" upon some representations of the collective Self and not others. Yet, this dependence is not a reliance solely upon the verbally expressed words themselves ("good" or "evil"). Rather, these words are politically consequential precisely because they touch upon - or are felt to touch upon - a deeper nerve that such words are believed by audience members to express. This "dependence" must be unfolded further. It is not just any construction of a Self that matters - to be linguistically cornered by a particular representation means that there is an investment by an audience in this image/Self. Thus, the effects of what Bially Mattern calls the representational force of soft power likely lie in the dynamics of affective investment in particular linguistic representations, the attachments to which then produce the possibility that an audience may be rhetorically cornered by sticking to this attachment.

While Hayden and Bially Mattern are emphasized here because they are the few studies in the soft power scholarship that develop attraction as a discourse-based phenomenon, the gaps in their work are symptomatic of larger shortcomings in the IR discourse and identity literature more 
broadly. Just as Hayden and Bially Mattern's linguistic models downplay the mechanisms by which narratives emotionally resonate with audiences, IR's understanding of discourse mostly neglects to unpack the relationship between affect and discourse. To be sure, in recent years discourse scholars - particularly poststructuralists - have made strides in detailing the role of language in the construction of identities. Milliken's (1999: 229-30) helpful summary of the key commitments of a discourse approach helps to illustrate these gaps. First, discourses are understood as "structures of signification which construct social realities" (Milliken 1999: 229). That is, material factors do not naturally emit meaning, but are made meaningful through peoples' descriptions about them. This means, secondly, that "discourses are productive of the things defined by the discourse" (Milliken 1999: 229). Discourses make sensible some ways of being and acting in the world while excluding or silencing other identities as marginal. Third, the focus on the productive power of discourse leads to a commitment to studying how dominant discourses are always unstable, in need of constant work to maintain their "regimes of truth," which makes them contingent and open to change (Milliken 1999: 230). Hansen's (2006: 18-23) discussion of the ontology of linguistic construction is also helpful here. As she contends, language "is a system of differential signs, and meaning is not established by the essence of a thing itself but through a series of juxtapositions, where one element is valued over its opposite" (Hansen 2006: 19). This view of meaning as constructed through the discursive juxtaposition of one sign valued over another (us/them, good/evil, etc.) leads to a conceptualization of identity as relationally constructed through its valuing via "others," yet is also unstable and thus open to contestation (Hansen 2006: 19; see also Campbell 1998; Doty 1996; Epstein 2008). Most of this poststructuralist work in IR on discourse, then, rightly focuses on deconstructing narratives of identity, demonstrating its relational construction through juxtapositions of differential signs, and emphasizing its historical contingency and instability. 
Yet, most of this work neglects to more fully unpack how discourses emotionally resonate with audiences beyond their socio-linguistic constructedness as such. To be sure, IR poststructuralists have laid important ground for approaching the issues of attraction and affect, as Ross (2006: 211) has pointed out, by “addressing the inarticulable dimensions of identity" through work on issues such as performativity, trauma, and memory. Moreover, recent work on the visual aspects of world politics (Hansen 2011; Williams 2003) has pointed to innovative ways in which to conceptualize meaning and discourse. Overall, however, IR discourse approaches have tended to offer relatively limited conceptualizations of discourse. Recent work in political theory has thus critiqued prevailing poststructuralist conceptualizations of discourse along these lines. For example, Glynos (2001: 195, emphasis in original) asks can a theory of discourse account for how a discourse "grips its subjects, of how ideology exerts its hold over us," given its socio-historical contingency? In other words, given that we now understand politics and identities to be socially constructed through language and thus contingent and contestable, is it possible to take further steps and ask how discourses appeal to and "grip" subjects beyond their mere constructedness? Alcorn (2002: 20, emphasis in original) asks a similar question: if "the subject is pushed by discourse, we need to describe clearly how this pushing occurs. Is pushing an effect of the simple exposure of discourse to the subject, or is pushing somehow a more complicated act, an effect especially responsive to particular words, feelings," and affective effects? If so, then power and social change entail much more than the binaries and signification structures that most poststructuralists tend to emphasize. "Changes in meaning ... are not the effect of instant change in signification. Important changes in meaning require significant changes in feeling. These changes are not instant permutations in relationships of signifiers; they require slow changes in libidinal investments" (Alcorn 2002: 112). Along the same lines, Stavrakakis (2007: 166) argues that "focusing on the symbolic aspects of political identity - although a necessary step . . is not 
sufficient in order to reach a rigorous understanding of the drive behind identification acts and to explain why certain identifications (old or new) prove to be more forceful and alluring than others.” In asking "is identity construction merely a semiotic play?” (Stavrakakis 2007: 193), Stavrakakis (2007: 166) contends that poststructuralism "has often employed models of subjectivity reducing it to a mere linguistic structure" at the expense of unpacking the affective aspects that would seem to offer a fuller understanding of the power of discourse and identity.

The following sections probe these questions and further develop soft power attraction along the lines suggested above. The next section turns to the IR emotions literature to draw upon a number of insights regarding the importance of affect to the construction of identity. The next section turns to recent work of Ernesto Laclau to draw together insights regarding affect and discourse, and develops the key notion of affective investment. In the subsequent section, the paper offers an empirical illustration of the role of affect in US efforts to construct its "attractiveness" in the war on terror following September 11, 2001.

\section{Soft Power, Attraction, and Affect}

To argue that soft power efforts at constructing attractiveness are based upon not only identity and language but also in investments of affect, it must be shown that affect plays a central role in identity and the power of discourse. While there is now a growing literature on the role of affect and emotion in global politics, ${ }^{3}$ several scholars have been specifically concerned about the role of emotion in the construction of political identities.

Many of these scholars note that despite receiving relatively little attention in tradtional IR approaches, identities are tightly bound to the forces of emotion. ${ }^{4}$ Mercer (2006: 298), for instance, contends that identity "is a feeling," and that to neglect it is to offer incomplete accounts of identity politics. "Other variables contribute to identity, but even in the case of ideas or material interests it is an emotional connection with a group that gives identity its power" (Mercer 
2006: 297). From another perspective, Ross (2006: 210) suggests that affect can help to account for how "identities are internalized below the level of consciousness." Affect is not simply private individual experience, but rather a phenomena whose circulations often constructs collective identities. Affects, in this sense, "are nonsubjective - they do not define the self but exist as strata, alongside the numerous other habits, memories, and beliefs that together comprise a particular construction of the self" (Ross 2006: 213). Harding and Pribram (2002: 418) similarly examine "some of the ways the emotions are constituted and operate upon the social and individual body/psyche to create a series of specific effects." Many such effects involve the amplification of categories of self and other, as Hutchison (2010) and Sasley (2011) detail. For Hutchison (2010), emotions are often key to rebuilding collective identity after trauma. Sasley (2011:466) contends that images of self and other are often built upon "emotional scaffolds." "States can thus only identify themselves as themselves when they feel that other states are different" (Sasley 2011: 466, emphasis in original). Fierke (2004: 484) likewise argues that "individual identity and emotion are bound up in the political unit. The emotions may remain disguised in individuals, but to be translated into political agency and identity, they must be put into words by leaders who give meaning to the individual experience by situating it in a larger context of group identity." Bleiker and Hutchison (2008: 123) sum up many of these insights in maintaining that "emotions are an intimate part of the attachments that bind individuals to particular objects and to others; they 'color' the relational ties that can come to constitute identity and belonging.",5

Thus, many in IR argue that emotion is a key element of identiy. Yet, as Hayden and Bially Mattern convincingly demonstrate, attractiveness is largely expressed sociolinguistically via narratives. How, then, can we draw together these two sets of insights - that attraction is produced through language and identity, and that emotion is central to identity (and therefore likely related to the construction of attractiveness)? And, how can these insights be incorporated 
into a fresh approach to soft power attraction? An answer comes Laclau's $(2004 ; 2005)$ work on affect and discourse and recent work by Steele (2010) on the aesthetics of power in IR. If Laclau brings together insights on language, identity, and affect/emotion through the notion of investment, then Steele illustrates how the aesthetic shaping of collective identities constitutes a key mechanism through which affective investment via attraction itself is elicited.

The notion of affective investment is one part of Laclau's larger project of delineating how hegemony - or, a society's “common sense" - is produced through the power of discourse. Much of this project, particularly since his oft-cited collaboration with Chantal Mouffe (Laclau and Mouffe 1985), has been to develop a theory of discourse that can account for how political identities are constructed, and to link these processes to how a society's "common sense" is produced. Laclau's work has been influential in socio-political theory in recent years (see Critchley and Marchart 2004), and is central to the "Essex School" of discourse theory (Howarth, Norval, and Stavrakakis 2000). Several IR scholars have used Laclau's framework (see Dietz 2001; Doty 1996; Hansen 2006; Solomon 2009), yet most of this work does not utilize the "affective turn" in Laclau's most recent work. It is this recent focus on the role of affect in political discourse that marks its usefulness here. Specifically, Laclau has recently argued for the necessity to explore what makes discourses resonate with audiences beyond analyzing their sociohistorical contingency as such. Here Laclau draws a key distinction between "form" and "force." For him (2004: 326), current approaches to discourse analysis focus mainly on reconstructing the discursive "forms" which structure identities produced in language. One of the key virtues of such an approach - as many in IR have discussed (Campbell 1998; Milliken 1999) - lies in how such analyses reconstruct and make explicit the ways in which words and narratives are articulated together to produce meaningful understandings of "us" and "them." 
Yet, Laclau argues that additional theoretical and empirical steps should be taken. Even as analyses of discursive "forms" or structures have brought substantial insights, they cannot fully grasp the "force" which can account for subjects' investments in these structures - "something else has be brought into the picture" (Laclau 2004: 326). The "different signifying operations to which [most discursive analyses focus] can explain the forms the investment takes, but not the force in which the investment consists" (Laclau 2005: 110, emphasis in original). Consequently, Laclau argues that the next step in discourse and identity research should be to examine how such investments endow discourses with the resonance that they often have. For him, such investments are rooted in affect. "It is clear, however, that if an entity becomes the object of an investment as in being in love, or in hatred - the investment belongs necessarily to the order of affect (Laclau 2005: 110, emphasis in original). Affective investment, then, pertains to the anchoring forces that bind subjects to their identities and particular kinds of discourses. The concept of affective investment is key here for several reasons. First, if discursive structures constitute the system within which subjects and identities are constructed (as many in IR have detailed), these structures alone cannot fully account for the potency of identities. Language must be infused with affect, in a sense, in order for it to have the "force" that it often has. Put differently, words alone often cannot carry the power that they often have - the force of affect is needed to explain how words resonate with audiences and have political effects beyond their mere verbal utterance as such. "Without this intensity or force (that is, without [affective] investment)," Laclau argues (quoted in Glynos and Stavrakakis 2010: 6), "there would be no discursive structure in the first place." Discourses need an affective push or stimulant for their articulation - "the complexes which we call 'discursive or hegemonic formations' ... would be unintelligible without the affective component" (Laclau 2005: 111). Affect, in this sense, is a key component in the construction of meaning and subjectivity itself. Subjects and identities are structured through discourse, but there 
must be an investment of affect in discursive structures in order to (partially) stabilize them in the fluidity of language. Yet, insofar as IR scholars have largely focused on meaning-making at the discursive level (what Laclau calls "form"), they have largely neglected how this is underpinned and sustained by affect.

Second, and closely related, the notion of investment is needed to help conceptualize the tricky relationship between affect and discourse. For Laclau, this relationship is an intimate one, and cannot be fully separated. "Affect is not something which exists on its own, independently of language; it constitutes itself only through the differential cathexes of a signifying chain. This is exactly what 'investment' means” (Laclau 2005: 111). Although affect is not coextensive or reducible to discourse, neither is it completely separable from it, for a specific conceptual reason. Since, in a discursive perspective, there is no "natural" link between words and the objects, identities, etc. that they purport to express (see Hansen 2006: 15-36), an investment is needed to explain this linking in the first place. Without a linkage of this kind - an element that is in some sense distinct from yet closely intertwined with discourse - it would be difficult to explain how the perceived linkage between words and their purported identities, objects, etc. is produced. In Laclau's words (2004: 300), "this link being essentially contingent, there is no logical connection between representative (signifier, word) and what it represents - there is no 'natural' passage from one to the other (this is why a 'radical investment' is required, the latter involving an affective link between two objects)." In this view, then, affective investment is a key link between, on one hand, identities constructed in language and, on the other hand, the "force" that imbues linguistic identities with their potency and binding power. The attachment of signifiers to signifieds (e.g., words and the entities that words purport to represent) is dependent upon an affective push prompting the construction of this linkage. 
If the concept of investment connects identity, language, and affect - and thus offers a theoretical argument for the workings of attraction in soft power - then recent IR work on aesthetics helps to more fully draw out the political mechanisms through which such investments are elicited. One reason why a turn to aesthetics is helpful here is that an increasing number of scholars contend that aesthetic insights are well-suited for grasping aspects of power which traditional social scientific models often have trouble fully capturing - including the "intangibles" which Nye has attempted to grasp through the notion of attraction. Bleiker (2009: 61), for example, argues that "an appropriate appreciation of emotions can be addressed through a more active engagement with aesthetic approaches." In particular, the work of Steele (2010) is helpful in understanding how attraction as affective investment is elicited through agents' - particularly states' - aesthetic work in fashioning their identities. As Steele (2010:4) argues, more "than the material basis of power, the aesthetics of power is made possible by the psychological and emotional connections that humans have toward a corporate body of power" such as a state. Steele argues that aesthetic and emotional dimensions of politics are best understood not as "deviations" from rationality, nor as purely individualistic motivations. Rather, just "like the process of aesthetic self-creation the individual engages in, the aesthetics of power is manifested not just in images but also in styles of discourse" (Steele 2010: 5).

Steele argues that there are multiple aspects of aesthetic power: psychological, imaginative, and rhythmic. The psychological strata of power refers to the "psychological connection established between the individual citizen and the idea of the nation" through which "power can maintain its hold over the "masses"” (Steele 2010: 29). Power works "best" when those who are bound by it do not realize the power of the bond they share. "Individual subjects are involved with power and submit to it because it fulfills their psychological needs, especially on the rare occasions it is exercised, and perhaps especially when it is violently expressed" (Steele 
2010: 29). Concurrently, the imaginative aspects of power are at work when a projected ideal image of the collective Self is assessed against an agent's empirical actions. To maintain a consistent (and hence secure) sense of Self, agents continually project an idealized image of oneself over which one is perceived to maintain power and control (Steele 2010: 32). This process is always one where aesthetic sensibilities are involved - the subject's image of itself (such as a nation's image of itself) is often imbued with pleasing features such as beauty, strength, and so on. Finally, power often has a rhythmic dimension related to movement, style, and ritual. As Steele (2010: 36, emphasis added) argues, "in terms of rhythm, a narrative smoothes out and provides coherence to the active self." The pomp and circumstance of public rituals and ceremonies, such as political inaugurations, anniversaries, and war victories express the aesthetics of rhythmic power and "presupposes a baseline of affect" (Steele 2010: 41, emphasis in original).

Theorizing the linkages between these phenomena not only adds an important new dimension to extant work on discourse and identity in IR. It also contributes fresh perspectives to current IR work on affect in two ways. First and most explicitly, a focus on affective investment provides a conceptual anchor for thinking about the interweaving relationships between three of IR's key contemporary concerns - discourse, identity, and affect. Theorizing how investments of affect function as the "force" or bonding that connects subjects to their identities offers a more complete picture of the power of language and identity beyond their linguistic structuring as such (as discussed above). Although the co-constitution of language and identity has been a focus in IR for some time, and although the IR affect/emotions literature has persuasively argued that emotions are an important part of identity (Bleiker and Hutchison 2008; Ross 2006), this literature has yet to fully conceptualize the specific role of affect in these processes. Second, this approach offers a way to think about affect and power - an issue the IR affect/emotions literature also has yet to adequately develop. Although some recent analyses of emotions in IR do implicitly discuss 
issues of power (see Crawford 2000; Hutchison 2010), explicit theorization of the function of affect in the dynamics of power has been mostly lacking. This is key because as Barnett and Duvall (2005: 42) argue, power is often a core feature of both relations between agents and in agents' social constitutions. A focus on affective investments in discourses of attraction offers a way to bring together these two forms of power that often remain underspecified in Nye's own work (Lock 2010: 35). ${ }^{6}$

The following section analyzes how some of these dynamics empirically play out in a specific case. The US-led war on terror offers an apt case not only because it is one in which Nye and other soft power scholars have often intervened (Nye 2004; Williams 2007). It also provides a vivid example of how soft power practices of attraction can be more comprehensively understood by accounting for affective investments elicited and cultivated through narrative and aesthetic presentations of collective identity.

\section{American Attractiveness and Affective Investment in the War on Terror}

Since September 11, 2001, Nye has consistently called for the US to more actively cultivate its soft power capacities while still advocating hard military power where necessary. "When we discount the importance of our attractiveness to other countries, we pay a price" since the "attractiveness of US policies can and does influence [other states'] degree of cooperation" (Nye 2004: 129, 131). In various ways, many scholars have focused on the US government's soft power efforts that functioned to promote American attractiveness after 9/11. While there is no doubt that for much of the post-9/11 period US attractiveness dipped significantly (see Aysha 2005; Katzenstein and Keohane 2007), there have been "both successes and failures" at the same time (Schneider 2005: 160). Much of this literature has focused on the linguistic efforts of government officials after $9 / 11$ to craft a coherent narrative of the events. Many of these studies analyze how the Bush administration constructed an identity narrative that portrayed the war on 
terror as one of "good against evil" and "civilization versus barbarism." These linguistic binaries are drawn upon to explain why American audiences accepted the idea of conducting a "war on terror" (Croft 2006; Krebs and Lobasz 2007). Nye (2004: 119-21) himself also suggests that the war on terror narrative was aimed at constructing American attractiveness after 9/11.

Yet, what was often key to this narrative was the attempt to craft US identity as attractive to both Americans and to global audiences. Put in Steele's (2010: 5, emphasis added) terms, just like "the process of aesthetic self-creation the individual engages in, the aesthetics of power is manifested not just in images but also in styles of discourse" deployed by state officials which constructs an identity narrative that is politically resonant. The power of the war on terror narrative, then, stems not only from the verbal expression of words themselves, but from the affective effects that these words produce with audiences. The language of the war on terror was perhaps a quintessential case.

Jackson (2005) has exhaustively detailed much of the war on terror narrative. His analysis helps to draw out the specific aesthetic features of the language deployed, and how this aesthetically-crafted narrative constructed an attractive American identity (to the extent that it did). Two narrative strands in particular illustrate this: the construction of a "good" America (in contrast to "evil" terrorists) and the articulation of the war on terror as a "good war." Jackson here draws upon IR identity research which argues that the social construction of identity is continually defined against an other, ${ }^{7}$ in this case, "the terrorist enemy is the 'enabling other' of the American 'self'" (Jackson 2005: 76). The American response to the attacks had to be narrated through a “positive conception of American foreign policy; even if military action caused much suffering, it proceeded from noble and virtuous intentions; America was a force for good in the world despite television footage which might show otherwise" (Jackson 2005: 76). American identity was articulated in terms of a "great nation, a freedom-loving nation, a compassionate nation, a nation 
that understands the values of life ..." and in terms of the "true strength of character and kindness of the American people" (Bush 2001c; Jackson 2005: 77). In a similar manner, the war on terror itself was narrated in terms of a "good" or "just" war. As President Bush (2001b) stated, "Whether we bring our enemies to justice, or bring justice to our enemies, justice will be done." The US "will go forward to defend freedom and all that is good and just in our world" (Bush 2001a).

Viewed through an affective and aesthetic lens, this narrative resonated not merely because it structurally differentiated an American identity from a "terrorist" other (in Laclau's terms, discursive "form"). More substantially, the aesthetic features of the language itself helped to entice audiences and cultivate affective investments ("force") in the identity constructs that it offered. As Steele (2010: 77) argues, narratives - such as the war on terror - involve the rhythmic, psychological, and imaginative aesthetic strata of power. The war on terror narrative actively cultivated each of these aesthetic strata of audiences. First, the sheer constancy and stream of speeches, press briefings, color-coded terror warnings, and so on constituted an overlapping series of public articulations of the narrative in different contexts, which speaks to the rhythmic aesthetics of power. As Ross (2006: 213) notes, "denouncing Saddam Hussein, broadcasting homeland security warnings, and memorializing $9 / 11$ - all made it possible to sustain public enthusiasm for continuing the military response [after Afghanistan] to Iraq." Other public rituals associated with the war on terror narrative - notably President Bush's fighter jet landing on the US aircraft carrier Abraham Lincoln in May 2003 - vividly illustrated the rhythms and movements associated with the aesthetics of power. Moreover, Toal (2003: 859-60) argues that through mass repetition the very phrase " $9 / 11$ " itself became a symbolic marker "of the desire to affirm that America 'still stands tall,' the desire to appear 'powerful,' 'resolute,' and 'dominant"' in the midst of trauma. Second, the psychological strata of aesthetic power was frequently on 
display whereby audiences were drawn to identify and emotionally connect with the collective construct of the nation through these aesthetic productions. Jackson (2005:129) points out that President Bush often conflated himself as President with the nation, coaxing an audience to identify with his particular constructions of "America." The "mixing of 'I' and 'we' in the same sentence rhetorically joins the individual president - with the (grammatically) united and purposeful nation" (Jackson 2005: 129). Moreover, the imaginative aspects of aesthetic power were engaged insofar as these public statements projected an "ideal" of the American nation-state - a state that (it was implied) would soon be "healed" from the trauma of the attacks if the new "war on terror" is fully carried out. In this sense, Burkitt (2005: 685) finds that "the seductive image was held out as a safe and secure world for oneself, one's family, friends, community, and nation."

Moreover, there is significant evidence that the war on terror narrative was attractive to many and resonated widely with both American and global audiences in the months following 9/11. Polling data from both the US and other countries show relatively high levels of public support for the US's counterterrorism efforts in late 2001 and throughout most of 2002. Indeed, Katzenstein and Keohane (2007: ix) remind us that "until the run-up to the Iraq War, polls consistently showed that pro-American sentiments, worldwide, dominated anti-American sentiments by a wide margin." Within the US, many polls showed widespread public support for "war on terror" policies after 9/11 (Lustick 2006: 16-19). Regarding global public opinion, Chiozza (2007) analyzes the results of the 2002 Pew Global Attitudes Survey, which asked respondents in forty-two countries of their opinion toward the US, of which majorities expressed positive attitudes. Of "all those who expressed an opinion (91 percent of the interviewees), 43.3 percent expressed a 'somewhat favorable' opinion and 21.3 percent expressed a 'very favorable' opinion [together, 64.6 of respondents expressing an overall positive view], thus revealing anti- 
American sentiment was a minority view in the world" (Chiozza 2007: 96). Although widespread, these results varied by region. Positive views of the US were prevalent in "Ghana, Guatemala, Honduras, Nigeria, the Philippines, Poland, Uzbekistan, and Venezuela." Interesting, even in then perceived-to-be-anti-American France and Germany, 64.4 percent and 61.1 percent, respectively, expressed pro-American sentiments (Chiozza 2007: 96).

The 2002 survey also lends support to the argument that international audiences expressed pro-American attitudes not only because of what the US “is" in a general sense (an open, democratic society, etc.), but that they also expressed specific support for American "war on terror" efforts. In "the summer of 2002, a majority of respondents in the industrial democracies of western Europe and Canada, in eastern Europe, in South Asia, and in East Asia said that they favored such efforts" (Chiozza 2007: 100; see also Holsti 2008: 43). However, one region where these attitudes were not expressed was in the Middle East and Pakistan, "where popular dislike of the United States was ripe and rampant" (Chiozza 2007: 97). Overall, though, the "voice of the people in 2002 predominantly had a pro-American accent" (Chiozza 2007: 97). This is also significant given the timing of the polls, which were conducted mostly between July and October 2002 (Chiozza 2007: 96). Large percentages of global public opinion supported US "war on terror" efforts long after President Bush's stark dichotomization (his "either you are with us, or you are with the terrorists" statement before a joint session of the US Congress on September 20, 2001) circled around the world in the international media. Thus, although the run-up to the Iraq War in March 2003 had a significant impact and changed international public opinion, throughout the months and year following 9/11 US soft power efforts at attracting public opinion to its side worked relatively well.

All of this returns us to the conceptualizations of the social dynamics of soft power developed above. By drawing together the conceptual strands of affect and language, the core 
dimension of soft power - attractiveness - can be theorized as a process of affective investment in constructs of identity that soft power efforts aesthetically promote. Returning to the recent trend of focusing on the role of language in soft power - most developed by Hayden (2012) and Bially Mattern (2005) but building upon the wider IR discourse and identity literature - helps to draw out the contribution of thinking about soft power in terms of affective investment. For Hayden (2012), soft power efforts are "symbolic in that public diplomacy should not be obviously selfreferential, but rather should demonstrate credibility through how its actions enable identification with the United States in some fashion" (Hayden 2012: 239, emphasis in original). This relationship between identification and symbolic expression is key to Hayden's re-working of soft power. This "would include attempts to cultivate so-called alluring positive attention as well as attempts to symbolically establish the perception that values, ideas, and cultures are shared in a compelling way. Attraction, as a soft power behavior, would be an invitation to recognize a shared experience of being and perspective" (Hayden 2012: 45). Attraction, allure, sense of shared being - while Hayden is correct to point out that these phenomena are all related to narrative processes, he nevertheless neglects to unfold their intrinsically affective and aesthetic features. The affectively-charged war on terror narrative was politically resonant not simply because of the symbolic expression (in Laclau's terms, the "form") of the words themselves after all, there were other narratives briefly circulating after $9 / 11$ yet did not resonate to the same degree as the war on terror. As Croft (2006: 113-15) details, some narratives at the time framed September 11, 2001 and responses to it not as an expansive "war on terror," but as an attack by specific Saudi Arabian radicals, and as a criminal act. What helped to "cultivate so-called alluring positive attention" and a "compelling" war on terror narrative was through its aesthetic presentation, which helped to facilitate affective attachments and investments in the narrative of identity that the war on terror produced. 
Like Hayden, Bially Mattern views attraction as language-based, yet views American attractiveness in the war on terror through the lens of "representational force." For her (2005: 604), the "manner in which the US represented its war on terror in the early post-9/11 days contained in its very structural logic a promise of unbearable subjective harm to particular states unless they abided the American viewpoint." US officials drew a stark line between "good" and "evil," and for Bially Mattern this illustrates why soft power in this case "was not so soft." "For members in the audience whose subjectivities depended in important part on narrative 'realities' about being on the 'good' side of the good/evil divide, this creates a trap. The 'nonchoice' was either to accept the US-articulated 'reality' of its own attractiveness . . . or deny it and contradict the logic and integrity of the narratives that inscribed their 'goodness"' (Bially Mattern 2005: 606, emphasis added). Audiences' subjectivities presumably did indeed "depend" upon some representations of collective identity and not others. Yet, if it is this "dependence" which was the aspect of audiences' subjectivities that was felt to be threatened with a linguistically coercive narrative, then the features of this "dependence" must be more fully unpacked. For Bially Mattern, this lies in having a consistent identity narrative. Narratives which threaten this consistency with a "forced choice" of being "good" or "evil" linguistically coerce audiences into placing themselves into the speaker's preferred identities. Yet, wanting to be on the "good" side of the narrative must consist on some level of being invested in seeing oneself as "good" and not "evil." For the representational force of the war on terror to work, this "dependence" must take the form of an investment in the very words and narrative that are felt to be threatened in the first place.

The "dependence" upon a consistent narrative in Bially Mattern's account and the symbolic facilitation of identification in Hayden's framework cannot work on a symbolic or narrative level alone. The power of the war on terror narrative does not rely solely upon the 
verbally expressed words themselves ("good" or "evil"). Rather, these words are politically consequential precisely because they touch upon - or are felt by audiences to touch upon - a deeper nerve or "essence" that such words are believed by audience members to express. Here is where the weaknesses of the prevailing views of language discussed above - and the key distinction between linguistic "form" and "force" - come into effect. Put into Laclau's (2005) terms, even as these analyses of the linguistic "forms" of US attraction offers insights, they neglect to more fully grasp the "force" which account for audiences' investments in these structures. "Something else has be brought into the picture," Laclau (2004: 326) would contend. These "different signifying [e.g., linguistic, narrative] operations can explain the forms the investment takes, but not the force in which the investment consists" (Laclau 2005: 110, emphasis in original). "It is clear, however, that if an entity becomes the object of an investment ... the investment belongs necessarily to the order of affect (Laclau 2005: 110, emphasis in original). Narrative must be infused with affect in order for it to have the "force" that it often has, and it is this affective "something else" which must be brought into analyzing attractiveness if we are to more fully understand the soft power of these narratives. Hayden's framework - while rightly arguing that "a more inclusive reframing is to consider attraction behaviors as those that cultivate identification" through "alluring positive" attributes (2012: 45) - needs a mechanism which explains the link, on one hand, between attraction as expressed through the symbolic medium of narrative, and on the other, why some efforts at facilitating identification are more politically successful than others. Bially Mattern's framework - while rightly arguing that narratives like the war on terror often "work" because of their symbolic coerciveness - needs to conceptualize the ontologically prior move that accounts for those dimensions of audiences' identities which allows them to be linguistically coerced in the first place. A brief counterfactual helps to illustrate the stakes in this move. If, for some reason, a US president happened to have little legitimacy or 
credibility, to the extent that few outside of his core constituency paid heed to his words, then many audiences may care little about a perceived-to-be illegitimate leader's simple division of the world into categories of "good" and "evil." Such a president could verbally deploy the same narrative of coercion, yet it would likely gain little traction, and would successfully coerce few, because wider audiences may not be very invested in this particular leader's definitions of good and evil. In this case, the same narrative would be unlikely to successfully coerce since the key feature of affective investment in the narrative's categories would be absent. An affective investment in and attachment to a narrative that one must remain "good" and not "evil" is a way to account for some of these differences in outcomes. Moreover, it helps to begin to explain the characteristics of audiences' attachments to identities that create the very possibility of linguistic coercion in narratives such as the war on terror.

\section{Conclusion}

This paper has aimed to theoretically develop some of the under-analyzed - yet key aspects of soft power. While Joseph Nye originally developed the concept with the context of American concerns of post-Cold War decline, he and many others have more recently explored the role of soft power within the context of post-9/11 global politics. Although Nye has argued that soft power stems from a number of sources, one key attribute - attraction - is typically viewed as the quintessential soft power feature. Nye himself has detailed how official policy and a society's culture can help to foster a state's attractiveness, while other scholars have elaborated and demonstrated how attraction often lies in the dynamics of language and identity. Yet, few have analyzed soft power attraction in terms of its affective and aesthetic dynamics. Drawing upon insights from the literatures on affect and aesthetic power, the main contribution of this article was to theorize the neglected affective underpinnings of soft power by developing the concept of attraction in terms of affective investment. Drawing upon Laclau's distinction between "form" 
and "force," the argument was made that to more fully understand the power of language particularly soft power discourses - analyses should examine not only the discursive "forms" that structure identities, but also the affective "force" behind the emotional investments in those identities which more fully accounts for their power. Consequently, a key factor behind the effectiveness of discourses of attraction lies in the affective investments by audiences in narrative identities constructed by states' soft power efforts. In introducing affective investment into analyses of soft power, this paper has aimed at not only bringing into a dialogue a variety of literatures which often neglect each other's findings - such as the literatures on soft power, affect, and aesthetics. Its broader aim has been to build upon previous studies to probe more deeply into the workings of soft power and consequently political power more broadly. As Barnett and Duvall (2005) have argued, power may be viewed as capacities of agents, constraints upon action, as constitutive of identities, or as the power to produce the very categories through which others see the world. Developing soft power attraction as an affective-based dynamic opens the doors to further thinking about how affect is implicated in each of these other key categories of power.

In developing the affective underpinnings of soft power, this article leaves open a number of questions, and thus offers some potential avenues for further research into soft power. First, having laid some of the theoretical groundwork, the article suggests that future work may consider more specific criteria for evaluating some of the affect dynamics of the reception of soft power efforts. In doing so, such an effort would continue to follow-up other recent critiques of soft power which point to the need to emphasize its relational dynamics between agent and target subject (Lock 2010; Lukes 2005). For example, the question of whether elite discourse, public opinion polls, or perhaps evidence from other sites such as popular culture constitute sufficient evidence for successful soft power efforts remains open. Second, other work may explore the role of affective attachments in relation to other societal sectors which may function as sources of soft 
power. For example, Nye (2007: 165) points out that "economic resources can produce both hardand soft-power behavior. They can be used to coerce as well as attract ... A successful economy is an important source of attraction." This has interesting overlap with recent work examining the role of affect and subjectivity in political economy (see Gammon 2008; Langley 2010), which argues that market economics often function not solely according to cost-benefit rationality, but are also guided by identity politics and affective dynamics much like other politics. How affective attachments to market economics intersect with soft power efforts of attraction would facilitate more comprehensive and novel understandings of both phenomena. Moreover, given that perhaps the most significant global event of the last ten years was the 2008 financial crisis, there are interesting questions that remain regarding whether such crises affect the attractiveness of not only particular states' economic models (such as the United States'), but also if the neoliberal economic model more generally retains the attractiveness it once did. Further investigation into these sources of attraction would likely yield additional key insights regarding the myriad of ways in which soft power works.

\footnotetext{
${ }^{1}$ Virginia Senator Jim Webb stated that "I guess the phrase of the week is 'smart power,' ... I've been doing this a long time, in and out of government. People come up with different phrases"(New York Times, 2009).

${ }^{2}$ Nye (2004: $x$ ) also mentions that attraction sometimes works in conjunction with "seduction:" "Seduction is always more effective than coercion, and many values like democracy, human rights, and individual opportunities are deeply seductive."

${ }^{3}$ For a sample, see Bleiker and Hutchison (2008), Eznack (2011), Mercer (2010) Ross (2006), Sasley (2010).

${ }^{4}$ Crawford (2000) discusses that although realist and liberal approaches do not explicitly theorize emotion, they often implicitly rely upon assumptions about emotions.

${ }^{5}$ Arguably the norms literature in IR largely neglects emotions as potential motivation.

${ }^{6}$ It is worth noting that bringing affect and aesthetics into analyses of power likely complicates the notion of intentions in the exercise of power. For example, insofar as Nye's conceptions have largely been agent-based (Lock 2010), introducing affective investments complicates the conceptualization of target audiences' receptions of soft power efforts. Similarly, it remains unclear in Bially Mattern's (2005) account how the analyst can know the intent of representational force. Since language alone cannot fully account for the power of identity and discourse (see
} 
above discussion), representational force alone is insufficient for understanding not only its possible intentions but also its effects, and must be coupled with a focus on affective "force." ${ }^{7}$ For a review of this literature, see Berenskoetter (2010).

${ }^{8}$ Many have also analyzed the attraction of American popular culture in post-9/11 politics. See Croft (2006), Devetak (2005), and Nye (2004: 38, 46-7).

\section{References}

Alcorn MW. Jr. (2002) Changing the Subject in English Class: Discourse and the Constructions of Desire. Carbondale: Southern Illinois University Press.

Aysha EE (2005) September 11 and the Middle East Failure of US 'Soft Power': Globalisation contra Americanisation in the 'New' US Century. International Relations 19(2): 193-210.

Barnett M, Duvall R (2005) Power in International Politics. International Organization 59(1): 3975.

Berenskoetter F (2010) Identity in International Relations. In Denemark RA (ed.) The International Encyclopedia. Blackwell Publishing, Blackwell Reference Online.

Berenskoetter F, Williams MJ (eds) (2007) Power in World Politics. London and New York, Routledge.

Bially Mattern J (2005) Why Soft Power Isn't So Soft: Representational Force and the Sociolinguistic Construction of Attraction in World Politics. Millennium: Journal of International Studies 33(3): 583-612.

Bleiker R (2009) Aesthetics in World Politics. Basingstroke: Palgrave Macmillan.

Bleiker R, Hutchison E (2008) Fear no more: emotions in world politics. Review of International Studies 34 (S1): 115-135.

Bohas A (2006) The Paradox of Anti-Americanism: Reflection on the Shallow Concept of Soft Power. Global Society 20(4), 395-414.

Burkitt I (2005) Powerful Emotions: Power, Government, and Opposition in the 'War on Terror'. Sociology 39(4): 679-695.

Bush GW (2001a) Address to the Nation. September 11. http://articles.cnn.com/2001-0911/us/bush.speech.text_1_attacks-deadly-terrorist-acts-despicable-acts?_s=PM:US.

Bush GW (2001b) Address to Joint Session of Congress. September 20.

http://archives.cnn.com/2001/US/09/20/gen.bush.transcript/ (accessed May 27, 2010). 
Bush GW (2001c) Prime Time News Conference, The East Room. October 11.

http://georgewbush-whitehouse.archives.gov/news/releases/2001/10/20011011-7.html.

Campbell D (1998) Writing Security: United States Foreign Policy and the Politics of Identity. Revised Edition. Minneapolis: University of Minnesota Press.

Chiozza G (2007) Disaggregating Anti-Americanism: An Analysis of Individual Attitudes toward the United States. In Katzenstein P and Keohane R (eds) Anti-Americanisms in World Politics. Ithaca and London: Cornell University Press, 93-126.

Clinton HR (2009) Nomination Hearing To Be Secretary of State Statement before the Senate Foreign Relations Committee Washington, DC. http://www.state.gov/secretary/rm/2009a/01/115196.htm.

Crawford N (2000) The Passion of World Politics: Propositions on Emotions and Emotional Relationships. International Security 24(4): 116-156.

Critchley S and Marchart O (eds) (2004) Laclau: a critical reader. London and New York: Routledge.

Croft S (2006) Culture, Crisis, and America's War on Terror. Cambridge: Cambridge University Press.

Deiz T (2001) Europe as a Discursive Battleground: Discourse Analysis and European Integration Studies. Cooperation and Conflict 36(1): 5-38.

Devetak R (2005) The Gothic Scene of International Relations: Ghosts, Monsters, Terror, and the Sublime after September 11. Review of International Studies 31(4): 621-643.

Doty R (1996) Imperial Encounters: The Politics of Representation in North-South Relations. Minneapolis: University of Minnesota Press.

Eznack L (2011) Crises as Signals of Strength: The Significance of Affect in Close Allies' Relationships. Security Studies 20(2): 238-265.

Epstein C (2008) The Power of Words in International Relations: Birth of an Anti-Whaling Discourse. Cambridge: MIT Press.

Fattah K, Fierke KM (2009) A Clash of Emotions: The Politics of Humiliation and Political Violence in the Middle East. European Journal of International Relations 15(1): 67-93.

Fierke KM (2004) Whereof we can speak, thereof we must not be silent: trauma, political solipsism, and war. Review of International Studies 30(4): 471-491.

Gammon E (2008) Affect and the Rise of the Self-Regulating Market. Millennium: Journal of International Studies 37(2): 251-278. 
Glynos J (2001) The grip of ideology: a Lacanian approach to the theory of ideology. Journal of Political Ideologies 6 (2): 191-214.

Glynos J and Stavrakakis, Y (2010) Politics and the Unconscious: An Interview with Ernesto Laclau. Subjectivity. 3: 231-244.

Hansen L (2006) Security as Practice: Discourse Analysis and the Bosnian War. New York: Routledge.

Hansen L (2011) Theorizing the image for Security Studies: Visual securitization and the Muhammad Cartoon Crisis. European Journal of International Relations 17(1): 51-74.

Harding J, Pribram ED (2002) The power of feeling: Locating emotions in culture. European Journal of Cultural Studies 5(4): 407-425.

Hayden C (2012) The Rhetoric of Soft Power: Public Diplomacy in Global Contexts. Lantham: Lexington Books.

Hocking B (2005) Rethinking the 'New' Public Diplomacy. In Melissen J (ed) The New Public Diplomacy: Soft Power in International Relations. Basingstroke: Palgrave Macmillan: 28-43.

Holsti OR (2008) To See Ourselves as Others See Us: How Publics Abroad View the United States after 9/11. Ann Arbor: University of Michigan Press.

Howarth D, Norval A and Stavrakakis Y (2000) Discourse Theory and Political Analysis. Manchester: Manchester University Press.

Hutchison E (2010) Trauma and the Politics of Emotions: Constituting Identity, Security, and Community after the Bali Bombing. International Relations 24(1): 65-86.

Jackson R (2005) Writing the War on Terrorism: Language, Politics, and Counter-terrorism. Manchester and New York: Manchester University Press.

Katzenstein P, Keohane RO (eds) (2007) Anti-Americanisms in World Politics. Ithaca and London: Cornell University Press.

Krebs RR, Lobasz JK (2007) Fixing the Meaning of 9/11: Hegemony, Coercion, and the Road to War in Iraq. Security Studies 16(3): 409-451.

Kroenig M, McAdam M, Weber S (2010) Taking Soft Power Seriously. Comparative Strategy 29(5): 412-431.

Laclau E (2004) Glimpsing the future. In Critchley S, Marchart M (eds) Laclau: a critical reader. London and New York: Routledge: 279-329. 
Laclau E (2005) On Populist Reason. London and New York: Verso.

Laclau E, Mouffe C (1985) Hegemony and Socialist Strategy. London and New York: Verso.

Langley P (2010) The Ethical Investor, Embodies Economies, and International Political Economy. In Abdelal R, Blyth M, Parsons C (eds) Constructing the International Economy. Ithaca and London: Cornell University Press: 211-226.

Lock E (2010) Soft Power and Strategy: Developing a 'Strategic' Concept of Power. In Parmar I, Cox M (eds) Soft Power and US Foreign Policy: Theoretical, Historical and Contemporary Perspectives. London and New York: Routledge: 32-50.

Lukes S (2005) Power and the Battle for Hearts and Minds. Millennium: Journal of International Studies 33(3): 477-93.

Lustick IS (2006) Trapped in the War on Terror. Philadelphia: University of Pennsylvania Press.

Melissen J (ed) (2005) The New Public Diplomacy: Soft Power in International Relations. Basingstroke: Palgrave Macmillan.

Mercer J (2006) Human nature and the first image: emotion in international politics. Journal of International Relations and Development 9(3): 288-303.

Milliken J (1999) The Study of Discourse in International Relations. European Journal of International Relations 5(2): 225-254.

New York Times Online (2009) How 'Soft Power' Got 'Smart'. January 14.

http://opinionator.blogs.nytimes.com/2009/01/14/how-soft-power-got-smart/

Nye JS Jr. (1990) Soft Power. Foreign Policy 80: 153-171.

Nye JS Jr. (1991) Bound to Lead: The Changing Nature of American Power. Basic Books.

Nye JS Jr. (2002) The Paradox of American Power: Why The World's Only Superpower Can't Go It Alone. Oxford and New York: Oxford University Press.

Nye JS Jr. (2004) Soft Power: The Means to Success in World Politics. New York: Public Affairs.

Nye JS Jr. (2007) Notes on a soft-power research agenda. In Berenskoetter F, Williams M (eds) Power in World Politics. London and New York: Routledge: 162-172.

Nye JS Jr. (2008) Public Diplomacy and Soft Power. The Annals of the American Academy of Political and Social Science 616(1): 94-109.

Nye JS Jr. (2011) The Future of Power. New York: Public Affairs. 
Parmar I, Cox M (eds) (2010) Soft Power and US Foreign Policy: Theoretical, Historical and Contemporary Perspectives. London and New York: Routledge.

Ross AAG (2006) Coming in from the Cold: Constructivism and Emotions. European Journal of International Relations 12(2): 197-222.

Sasley BE (2010) Affective attachments and foreign policy: Israel and the 1993 Oslo Accords. European Journal of International Relations 16(4): 687-709.

Sasley BE (2011) Theorizing States' Emotions. International Studies Review 13(3): 452-476.

Schneider CP (2005) Culture Communicates: US Diplomacy That Works. In Melissen J (ed) The New Public Diplomacy: Soft Power in International Relations. Basingstroke: Palgrave Macmillan: 147-168.

Solomon T (2009) Social Logics and Normalization in the War on Terror. Millennium: Journal of International Studies 38(2): 269-294.

Solomon T (2012) 'I wasn't angry, because I couldn't believe it was happening:' Affect and Discourse in Responses to 9/11. Review of International Studies 38(4): 907-928.

Stavrakakis Y (2007) The Lacanian Left: Psychoanalysis, Theory, Politics. Albany: State University of New York Press.

Steele BJ (2010) Defacing Power: The Aesthetics of Insecurity in Global Politics. University of Michigan Press.

Sun J (2012) Japan and China as Charm Rivals: Soft Power in Regional Diplomacy. Ann Arbor: University of Michigan Press.

Toal G (2003) 'Just Out Looking for a Fight': American Affect and the Invasion of Iraq. Antipode 35(5): 856-870.

van Ham P (2005) Power, Public Diplomacy, and the Pax Americana. In Melissen J (ed) The New Public Diplomacy: Soft Power in International Relations. Basingstroke: Palgrave Macmillan: 4766.

Wang H, Lu Y (2008) The Conception of Soft Power and Its Policy Implications: a comparative study of China and Taiwan. Journal of Contemporary China 17(56): 425-447.

Watanabe Y, McConnell D (2008) Introduction. In Watanabe Y, McConnell D (eds) Soft Power Superpowers: Cultural Assets of Japan and the United States. Armonk, NY: M.E. Sharpe, xviixxxii.

Williams MC (2003) Words, Images, Enemies: Securitization and International Politics. International Studies Quarterly 47(4): 511-531. 
Williams MJ (2007) Theory meets practice: Facets of power in the 'War on Terror'. In Berenskoetter F, Williams MJ (eds) Power and World Politics. London and New York:

Routledge: 265-276. 